\title{
Improving On Fast-track Protocol for Post Cardiac Surgery Patients
}

\author{
Yi C Tham*, Zhihui Tan', Anna LW Tam, Shah S Sharad ${ }^{2}$, Kenny YK Sin ${ }^{1}$, Shaw Y Chia ${ }^{3}$, Kim K Ong ${ }^{1}$ \\ From World Society of Cardiothoracic Surgeons 25th Anniversary Congress, Edinburgh \\ Edinburgh, UK. 19-22 September 2015
}

\section{Background/Introduction}

Many risk factors have been shown to be independently predictive of the success of fast-track for post cardiac surgery patients. While a safe fast-track protocol is important, patient selection is crucial too in determining the success of fast-tracking patients.

\section{Aims/Objectives}

We aim to improve on our fast-track protocol by identifying risk factors affecting extubation time in our institution.

\section{Method}

For a total of six months duration, we non-selectively included all cardiac surgery patients admitted through our new post-anaesthesia care unit (PACU). We studied how patients' profile, comorbidities and operative data affect the success rate of extubation.

\section{Results}

107 of the total 145 patients admitted to PACU were able to be extubated. However, only $79(54.5 \%)$ patients were able to be extubated within four hours. Within the success group, we found that age (OR $=0.912 ; 95 \% \mathrm{CI}=0.044$ 1.779) and duration of ventilator weaning $(\mathrm{OR}=0.813$; $95 \% \mathrm{CI}=0.698-0.928)$ significantly influenced the extubation time with p-value of 0.040 and $<0.001$ respectively. Within the failure group, age $(\mathrm{HR}=1.061 ; 95 \% \mathrm{CI}=$ 1.018-1.105), EUROscore II ( $\mathrm{HR}=2.303 ; 95 \% \mathrm{CI}=1.416$ 3.748), cardiopulmonary bypass time ( $\mathrm{HR}=1.015$; CI $95 \%$ 1.005-1.025), aortic cross-clamp time (HR $=1.023 ; 95 \%$ $\mathrm{CI}=1.010-1.037)$ and post-operative inotropic usage $(\mathrm{HR}=2.892 ; 95 \% \mathrm{CI}=1.637-5.109)$ significantly affect failure of extubation with p-values of 0.005, 0.001, 0.004, 0.001 and $<0.001$ respectively.

\section{Discussion/Conclusion}

Through this observational study, we will be able to improve on our pre-operative patient selection based on their age and EUROscore II; and intra-operative decision based on the total cardiopulmonary bypass time and aortic cross-clamp time in order to fast-track cardiac patients by admitting them to PACU. Through this, fast-track protocol can be practiced safely to its many advantages.

\section{Consent}

Written informed consent was obtained from the patient for publication of this abstract and any accompanying images. A copy of the written consent is available for review by the Editor of this journal.

\section{Authors' details}

${ }^{1}$ Department of Cardiothoracic Surgery, National Heart Centre Singapore, Singapore, 169609, Singapore. ${ }^{2}$ Department of Anaesthesia, Singapore General Hospital, Singapore, 169609, Singapore. ${ }^{3}$ Department of Statistics, Singapore Cardiac Databank (National Heart Centre), Singapore, 169609, Singapore.

Published: 16 December 2015

\section{doi:10.1186/1749-8090-10-S1-A330}

Cite this article as: Tham et al:: Improving On Fast-track Protocol for Post Cardiac Surgery Patients. Journal of Cardiothoracic Surgery 201510 (Suppl 1):A330. 